\title{
南海西北次海盆深部热岩石圈结构及其对浅部 构造演化的控制
}

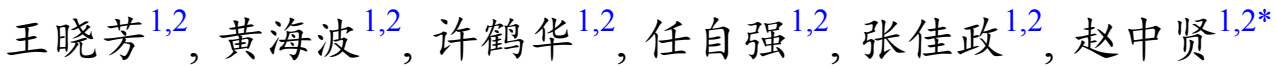 \\ 1. 中国科学院边缘海与大洋地质重点实验室, 中国科学院南海海洋研究所, 南海生态环境工程创新研究院, 广州 511458; \\ 2. 南方海洋科学与工程广东省实验室(广州), 广州 511458 \\ * 通讯作者, E-mail: zxzhao@scsio.ac.cn
}

收稿日期: 2020-07-30; 收修改稿日期: 2020-12-11; 接受日期: 2021-01-19; 网络版发表日期: 2021-05-11 国家自然科学基金-广东联合基金项目(编号：U20A20100)、南方海洋科学与工程广东省实验室(广州)人才团队引进重大专项项目(编号: GML2019ZD0104、GML2019ZD0204)、中国科学院青年创新促进会项目、中国科学院南海生态环境工程创新研究院自主部署项目(编号: ISEE2018PY02)、国家自然科学基金项目(批准号：41506063、41730532、91958212、91428205、42076077)和广东省基金项目(编号: 2020A1515010502、2017A030312002)资助

\begin{abstract}
摘要西北次海盆是南海扩张早期形成的一个特殊的构造单元，其周边被西沙海槽、中沙海台、珠江海谷等裂 谷和地块所围限, 演化出一系列海山和断裂带等复杂地质构造, 其深部构造伸展和岩浆活动均与岩石圈结构及其 变形密切相关, 但目前对其深部岩石圈结构的了解还较少. 文章通过收集西北次海盆及其周边地区的声纳浮标、

双船扩展剖面(ESP)、海底地震仪(OBS)、多波束和海陆联测等地震调查数据，详细获得其水深、基底、莫霍面 的深度数据. 根据热重力均衡方法精细计算得到南海西北次海盆及其周边地区的岩石圈基底埋深, 结果表明其深 度范围在25 110km之间, 在海盆区最浅埋深为 $25 \sim 60 \mathrm{~km}$, 陆缘增加至 $60 \sim 110 \mathrm{~km}$. 其中, 西沙海槽的南、北两侧的 岩石圈结构明显对称, 展现出具有天折裂谷特点的岩石圈深部结构和热状态.中沙海槽和中沙海台的岩石圈基底 埋深从60 km 向西南方向增加到70 km，与地表形态一致. 珠江海谷西侧岩石圈基底埋深在60 80km, 该区岩石圈厚 度的减薄与断层、凹陷的分布和岩浆活动有关. 西北次海盆和东部次海盆岩石圈基底埋深均小于 $60 \mathrm{~km}$, 最薄小 于 $46 \mathrm{~km}$. 结合大洋钻探、地震探测和浅部地形表明, 南海西北次海盆的成熟洋盆范围位于岩石圈基底埋深在 $46 \mathrm{~km}$ 等深线以内的区域，海盆周围的裂谷和离散地块的演化过程，同时受到浅部构造运动和深部热物质活动的 控制, 其岩石圈结构表现出强烈不均一性.
\end{abstract}

关键词西北次海盆, 热重力均衡, 洋陆转换带, 岩石圈厚度

\section{1 引言}

西北次海盆位于南海西北部的深水区, 其位置独 特, 构造演化复杂, 是南海地区的一个重要的地质构
造单元(图1). 其西部为西沙海槽, 是一条天折裂谷, 记 录着裂谷发生和停止的重要信息, 与南海北部陆缘一 起表现出NS拉张边界(Wang等, 2020); 海盆西南部为 中沙海台，作为坚硬的地块其似乎阻挡了西北次海盆

\footnotetext{
中文引用格式: 王晓芳, 黄海波, 许鹤华, 任自强, 张佳政, 赵中贤. 2021. 南海西北次海盆深部热岩石圈结构及其对浅部构造演化的控制. 中国科学: 地球科学, 51(7): 1150-1165, doi: 10.1360/SSTe-2020-0200

英文引用格式: Wang X, Huang H, Xu H, Ren Z, Zhang J, Zhao Z. 2021. The deep thermal structure of the lithosphere in the northwestern South China Sea and its control on the shallow tectonics. Science China Earth Sciences, 64(6): 962-976, https://doi.org/10.1007/s11430-020-9726-2
} 


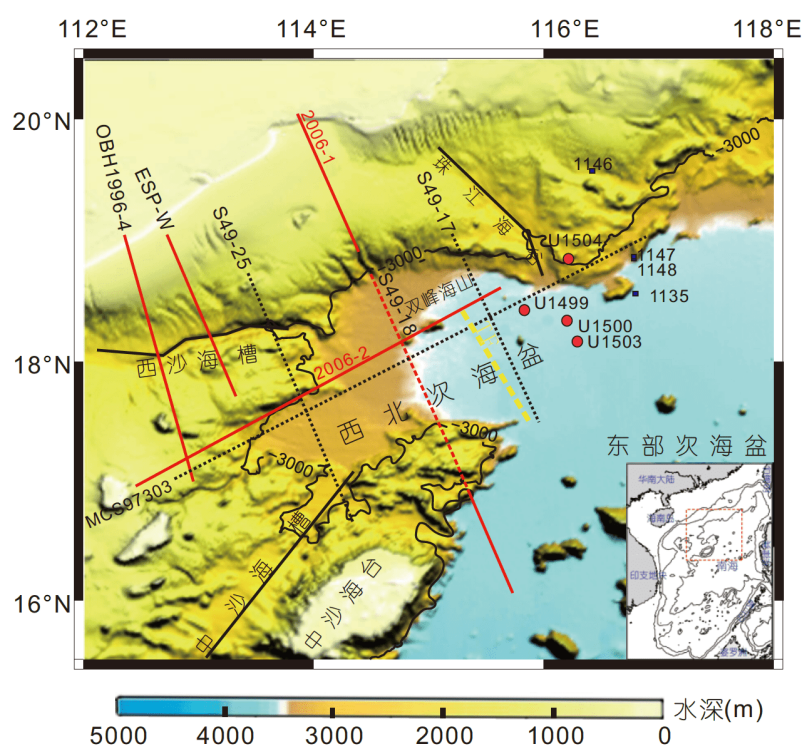

图 1 西北次海盆构造及水深图

红色实线代表主要OBS测线位置, 红色虚线代表多道地震测线位置, 黑色直线和折线标注了西沙海槽、中沙海槽和珠江海谷, 黑色曲线 是水深 $3000 \mathrm{~m}$ 等深线; 红色圆点代表主要的国际大洋钻探 (IODP367、368、368X)位置，蓝色方框是大洋钻探(ODP) 和国际大 洋钻探(IODP349)航次站位(Li等, 2014), 黄色虚线TF代表转换断层 (Larsen等, 2018; Sun等, 2018)

向西南方向的传播，造成海盆东北宽西南窄的分布形 态 (Sun等, 2009; Ding等, 2011; Huang等, 2020). 西北 次海盆与东部次海盆之间以一条转换断层为界, 反映 了南海扩张活动的传播和扩张脊的推进. 西北次海盆 内及其周边地区广泛分布着海山、海岭和海丘，是强 烈岩浆作用的结果(Gao等，2016). 因此，西北次海盆 经历了大陆岩石圈拉张破裂、海底扩张、裂谷天折与 岩浆的溢出等复杂的地质过程. 虽然其形成历史不长 (约32 25Ma)， 7 Ma(Briais等，1993; 丁巍伟等，2009; Ding等, 2011), 空间尺度不大, 是南海 3 个次海盆中最 小的一个, 但却保留了南海演化过程的各个阶段, 研究 其岩石圈深部结构对于我们了解年轻边缘海盆地的形 成机制具有关键的作用.

西北次海盆也是国际大洋发现计划(IODP)追踪洋 陆转换带的重要的位置. IODP在2017年和2018年对南 海北部陆缘分别进行了 $367 、 368$ 和 $368 \mathrm{X}$ 三个航次的钻 探(图1和表1). 从外缘隆起(OMH)到洋陆过渡带(COT), 再到早期洋盆区共分布7个站位(Sun等，2018；Jian等, 2018; Childress等, 2019), 其中, 陆壳最南缘为U1499站 位, 洋壳胚胎期为U1502和U1500站位. 这些钻探的岩
石学分析结果为确定南海洋陆过渡带的分布提供了重 要的依据(Larsen等, 2018). 然而, 西北次海盆北部地形 和磁异常条带识别的洋中脊C10(Briais等, 1993)都呈弧 形分布, 该区洋陆过渡带是否也具有类似特点? 这种分 布特点是因受力改变而成？还是深部热岩石圈构造和 热状态的影响所致? 由于缺乏直接的岩石圈结构观测 和研究, 这些关键科学问题尚无明确答案.

近年来我国在南海海域开展了大量的声纳浮标、 双船扩展剖面(ESP)、海底地震仪(OBS)和海陆联测等 地震调查工作(Qiu等，2001; Yan等，2001; Wang等, 2006; 郝天珧等, 2011; 吴振利等, 2011; 丘学林等, 2011; 徐辉龙等, 2012; 敖威等, 2012; Ding等, 2018). 这些探测取得了大量的研究成果, 识别出高速层(Nissen等，1995; Yan等，2001；Wang等，2006; 邱惁翔， 2010; Zhao等, 2010)和低速层(赵明辉等, 2004, 2007)等 具有特殊构造意义的速度异常层, 极大地丰富了对西 北次海盆及其周边地区深部结构特征的认识，为我们 向岩石圈深部构造的探索提供了非常有力的数据基础 和浅层约束.

由于大洋钻探和人工地震探测受深度和精度的限 制, 所获得对于岩石圈深部结构的认识仅停留在沉积 层基底和Moho面之上，南海岩石圈基底深度的详细刻 画结果却极其稀少，只存在个别剖面的计算(胡立天 等, 2019; 施小斌等, 2000). 主要的探测手段是依靠南 海周边陆区的地震台网资料，通过面波层析成像方法 得到岩石圈的 $\mathrm{S}$ 波速度结构，并根据 $\mathrm{S}$ 波速度变化特征 来获取岩石圈厚度(黄忠贤和胥區，2011；Tang和 Zheng, 2013; Yu等, 2017). 然而由于海域天然地震研 究存在站位分布不均缺点, 其结果不但分辨率低而且 存在较大的分歧(黄忠贤和胥饾, 2011; 夏少红等, 2014), 严重地制约了深部地球动力学的研究. 本文通 过收集和整理西北次海盆及其周边地区的地震数据 (图2), 提取地形(水深)和Moho面埋深，根据热重力均 衡方法(Artemieva, 2019)的精细计算, 得到岩石圈基底 的埋深. 以此研究和探讨西北次海盆及其周边地区的 深部构造和热状态与地表不同构造单元的响应关系.

\section{2 方法和数据}

\section{1 岩石圈中的重力均衡的原理和异常地形}

均衡是地球物理学的基本概念之一, 实现均衡的 
表 1 地震测线剖面及钻孔数据来源

\begin{tabular}{|c|c|c|}
\hline 数据类型 & 数据名称 & 数据来源 \\
\hline \multirow{3}{*}{$\mathrm{OBH}$ 测线数据 } & OBH 1996-2 & Wu等, 2009; 刘赛君等, 2011 \\
\hline & OBH 1996-3 & Xia等, 1998; 吴世敏等, 2001 \\
\hline & OBH 1996-4 & Qiu等, 2001 \\
\hline \multirow{11}{*}{ OBS测线数据 } & OBS 2006-1 & 吴振利等, 2008, 2011 \\
\hline & OBS2006-2 & 敖威等, 2012; 王强等, 2020 \\
\hline & OBS 973-1 & 丘学林等, 2011 \\
\hline & OBS $973-2$ & 阮爱国等, 2011 \\
\hline & OBS 973-3 & 黄海波等, 2011 \\
\hline & OBS 1993 & Yan等, 2001 \\
\hline & OBS 1995 & McIntosh等, 2005 \\
\hline & OBS 2011-3 & Pichot等, 2014 \\
\hline & TAIGER2009-2/3 & Eakin等, 2014 \\
\hline & OBS 3D-2011-2 & Zhao等, 2018 \\
\hline & OBS 2001 & Wang等, 2006; Zhao等, 2010 \\
\hline ESP测线数据 & ESP-E, ESP-W, ESP-C & Nissen等, 1995 \\
\hline \multirow{2}{*}{ 声纳浮标数据 } & 中美联合调查声纳浮标资料 & 李振五, 1984 \\
\hline & 南海海盆声纳浮标资料 & 刘金萍和阎贫, 2003 \\
\hline 多道地震数据 & 南海多道地震及资料 & $\begin{array}{l}\text { Franke等, 2008; Yan和Liu, 2004; 姜绍仁和周效中, 1993; } \\
\text { 姜绍仁等,1990a, 1990b; 周效中等, } 1993\end{array}$ \\
\hline \multirow{3}{*}{ 大洋钻孔数据 } & ODP184航次汇报 & 汪品先, 2019 \\
\hline & IODP349航次报告 & Expedition 349 \\
\hline & IODP367-368航次报告 & Sun等, 2018 \\
\hline
\end{tabular}

补偿深度并不为人所知, Pratt和Airy的经典概念假设 在地壳底部实现了均衡，而2019年，Artemieva在研究 欧洲克拉通岩石圈结构时, 提出热重力均衡算法, 认为 实现均衡的深度可能更深,并且通常预期补偿深度不 会比岩石圈的底部更深. 这与我们计算的南海西北次 海盆的地震剖面的结果类似，于是我们假设其重力均 衡面在岩石圈基底(Lithosphere-Asthenosphere Boundary, 简称 $\mathrm{LAB}$ ), 收集和整理了西北次海盆及其周边地 区地震剖面数据, 获得精确的水深和Moho埋深数据 (图2和表1), 为了消除边界效应的影响, 我们将南海目 前积累的地震剖面的地形(水深)和Moho面满足地壳 均衡, 这里指Airy均衡的条件, 见图3中的公式. 特别的, 为了使西北次海盆周边地区计算的岩石圈结构的结果 更加精确, 我们分别计算了典型人工地震剖面 OBS2006-1、OBS2006-2、OBH1996-4、OBS2007、 OBS2006-3和OBS1993对应的线性关系(见图4和图5).
将Airy均衡预测的地形与真实地形的偏差, 称为异常 地形(这里指地形与真实地形的偏差), 表示为 $A$, 绘制 于图6. $3000 \mathrm{~m}$ 水深的海盆区呈现正异常特征, 外部陆 壳和陆坡区呈现负异常特征.

本文中的异常地形是指实测地形与假设重力均衡 位于Moho面、根据Airy均衡计算的地形之间的偏差 (Artemieva, 2019). 理论上这部分异常地形并不能完全 归因于由岩石圈热异常引起的均衡地形, 它还可能包 含由岩石圈成分差异(如地壳成分差异等)引起的均衡 地形，以及由深部地幔黏性流动对岩石圈产生的长波 长动力地形成分(如Pari和Peltier, 2000; Hoggard等, 2016; Steinberger, 2016; Yang和Gurnis, 2016; Liu, 2020). 对于地壳成分差异的影响, 由于研究区内地壳 成分主要是陆壳、洋壳和洋陆过渡带, 其成分是有差 别, 但我们的计算模型中地壳的成分包括沉积层, 在 洋壳内沉积层较厚, 而且沉积层密度相对于陆壳上的 


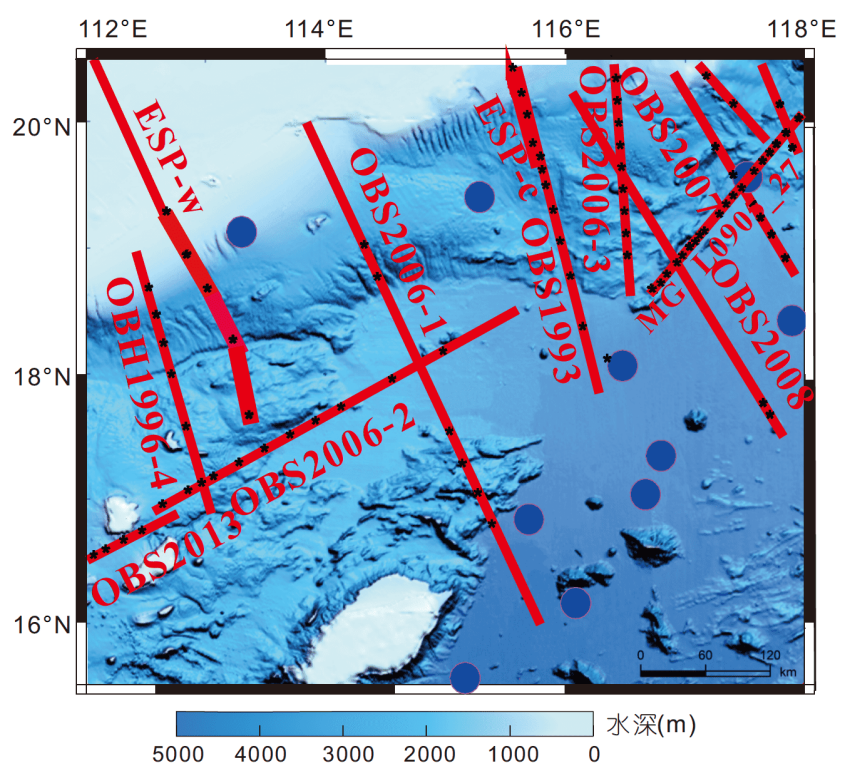

图 2 西北次海盆的地形图(水深)和主要地震数据计算得 到的岩石圈厚度数据集

所有的地震剖面和声纳浮标数据的参考文献见表 1 ，黑色花瓣和蓝 色圆点分别是根据OBS地震剖面和纳浮标计算得到岩石圈基底埋 深的点, 红色线是主要的地震剖面

沉积层密度要小(阎贫和刘海龄, 2002; Shi等, 2005; 任 建业等，2018)，也可以见我们计算的密度分布的结果 (见图13和图14)，因此地壳密度我们采用的是平均密 度，具体剖面的计算见图8. 对于动力地形，它是流体 力学的一个概念，通过流体内部流动产生非零垂直分 量的黏性应力形成的流体表面, 即形成一个动态地形. 它与地球表面地形的潜在相关性可以追溯到数十年前 最初发现的地球非水动力重力异常和大地水准面，二 者具有与 2 度球谐函数相对应的显著正值(Liu，2020). 而在南海西北次海盆及其周边地区，最新自由空间重 力异常(图7)和大地水准面异常值(张文涛，2019)基本 接近零. 并且本文研究区范围较小, 位于 $112^{\circ} \sim 118^{\circ} \mathrm{E}$ 和 $15.5^{\circ} \sim 20.5^{\circ} \mathrm{N}$ 之间，空间尺度小于 $10^{3} \mathrm{~km}$ ，所以即使
存在动力地形影响, 其相对变化规模理论上也不会很 大. 在东南亚和南海区域，前人对动力地形也做了一 些模拟和分析，但是对动力地形的幅度和波长等认识 存在很大分歧(Lithgow-Bertelloni和Gurnis，1997， Wheeler和White, 2000，2002; Xie等，2006). LithgowBertelloni和Gurnis (1997) 根据全球板块俯冲模型, 预 测了东南亚存在约 $1 \sim 2 \mathrm{~km}$ 动力沉降, 波长为 $10^{2} \sim 10^{3} \mathrm{~km}$. 然而构造沉降计算和理论沉降分析则发现东南亚仅存 在 $300 \mathrm{~m}$ 的异常沉降, 且波长较短为 $10^{2} \mathrm{~km}$, 认为这种 特征可能不是动力地形引起的, 而是陆缘伸展和前陆 作用造成的(Wheeler和White, 2000, 2002). Wheeler和 White (2000，2002)进一步指出Lithgow-Bertelloni和 Gurnis(1997)所预测的较大动力地形可以通过改变俯 冲板片密度和地幔黏度等来调节. 而且前人的研究结 果表明，较大的动力地形往往存在于构造活跃区域, 如美西白严纪平俯冲产生的大范围动力沉降 (Liu, 2015)或者新生代板内火山活动伴随局部的动力抬升 (Zhou和Liu, 2019). 在本文研究区域内, Xie等(2006)利 用全球地幔流模型也模拟预测了南海区域的动力地 形. 结果表明，在40 20Ma动力地形仅为 $0 \sim 100 \mathrm{~m}$; 在 20 0Ma, 动力地形则为 $-200 \sim 0 \mathrm{~m}$. 因此，根据Xie等 (2006)的模拟结果，在本文研究区内，40Ma以来的总 动力地形非常小, 仅 $-100 \mathrm{~m}$, 这与附近的琼东南盆地 构造沉降分析揭示的盆地新生代总沉降的理论值和观 测值相接近的结果一致(Zhao等, 2018). 通过以上分析 可以看出动力地形在本文研究区的影响较小, 与本文 计算的千米级别的异常地形(图6)相比，可以忽略. 因 此，本文近似地把异常地形归因于由岩石圈热异常引 起均衡地形.

\section{2 岩石圈中的温度异常和岩石圈基底埋深的计算} 由于影响岩石圈变形和重力均衡的因素有很多,

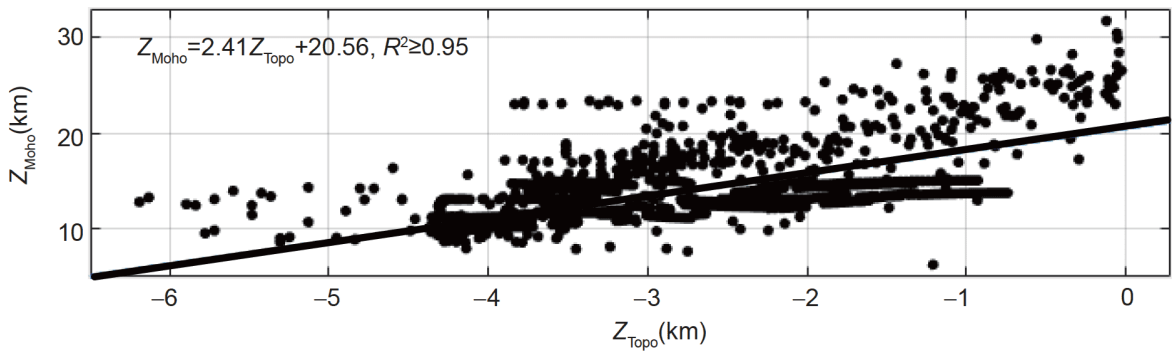

图 3 所有的数据点的Moho和地形埋深的线性关系 

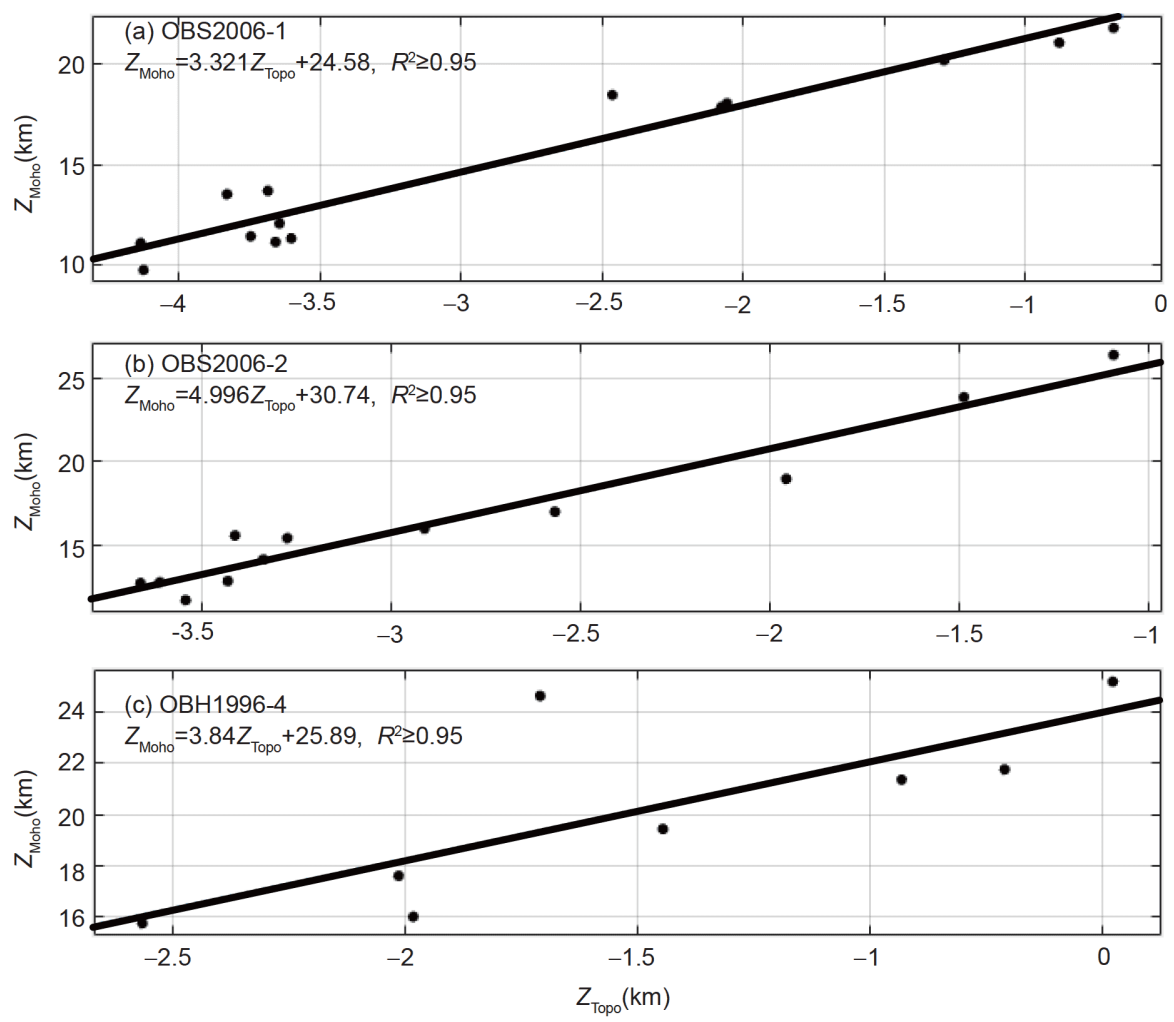

图 4 人工地震剖面OBS2006-1、OBS2006-2和OBH1996-4的Moho和地形埋深的线性关系

目前的计算和数值模拟不能实现满足所有的条件和控 制因素，这里我们只考虑岩石圈温度变化对地幔密度 异常起主要影响的假设(Deschamps等, 2002; Schutt和 Lesher, 2006; Simmons等, 2009). 异常地形是由岩石圈 地幔中的密度异常和岩石圈地幔厚度的变化引起的， 其中, 岩石圈地幔中的密度异常则是由温度变化引起, 地壳密度非均质性的影响由莫霍面深度变化补偿. 则 根据假设均衡面在岩石圈基底(LAB)，异常地形 $A$ 可以 表示为

$A \rho_{\mathrm{m}}=Z_{\mathrm{LAB}}\left[\rho_{0}-\rho_{\Delta T}\right]$,

其中 $Z_{\mathrm{LAB}}$ 是岩石圈基底的深度， $\rho_{0}$ 是岩石圈的原位密 度，即没有发生温度异常的岩石圈的密度，此时 $A=0 \mathrm{~km} . \rho_{\mathrm{m}}$ 是软流圈地幔密度, $\rho_{\Delta T}$ 是温度异常为 $\Delta T$ 时 的岩石圈平均密度. 温度异常 $\Delta T$ 是在整个岩石圈柱上 (从地表到岩石圈基底)取平均值，并且是相对于 $A=0 \mathrm{~km}$ 的参考点处的平均温度来定义, 而

$\rho_{\Delta T}=\rho_{0}(1-\alpha \Delta T)$,

其中 $\alpha$ 是热膨胀系数为 $3.5 \times 10^{-5} \mathrm{~K}^{-1}$.
由式(1)和(2)得

$\Delta T=A \rho_{\mathrm{m}} / Z_{\mathrm{LAB}} \alpha \rho_{0}$.

因此，通过公式(3)异常地形 $A$ 可以直接转换为岩石圈 中的温度异常 $\Delta T$.

同时,在 $T=0^{\circ} \mathrm{C}$ 时岩石圈(地壳加岩石圈地幔)密 度为

$\rho_{0}(0)=\left[2800 Z_{\mathrm{Moho}}+3300\left(Z_{\mathrm{LAB}}-Z_{\mathrm{Moho}}\right)\right] / Z_{\mathrm{LAB}}$,

其中, $Z_{\mathrm{Moho}}$ 和 $Z_{\mathrm{LAB}}$ 分别是Moho面和岩石圈基底的埋 深, 大块地壳的平均SPT(Standard pressure-temperature laboratory conditions, 即在 $0^{\circ} \mathrm{C}$ 、标准大气压的实验室 条件下)密度为 $2800 \mathrm{~kg} \mathrm{~m}^{-3}$ (包括沉积层), 该区有两种 不同的地壳: 陆壳和洋壳, 虽然洋壳的密度大于陆壳的 密度, 但是洋壳部分的沉积层较厚, 因此垂向平均密度 与周围的陆壳相差不大(见图8)，其中，密度的分布根 据正演重力资料处理软件，拟合自由空间重力异常见 图13和图14, 从而得到垂向单位面积上的平均密度.

于此同时，我们也可以通过本文中提供的地震剖 面进一步约束, 类似本文后面提到的图13 15. 大块岩 

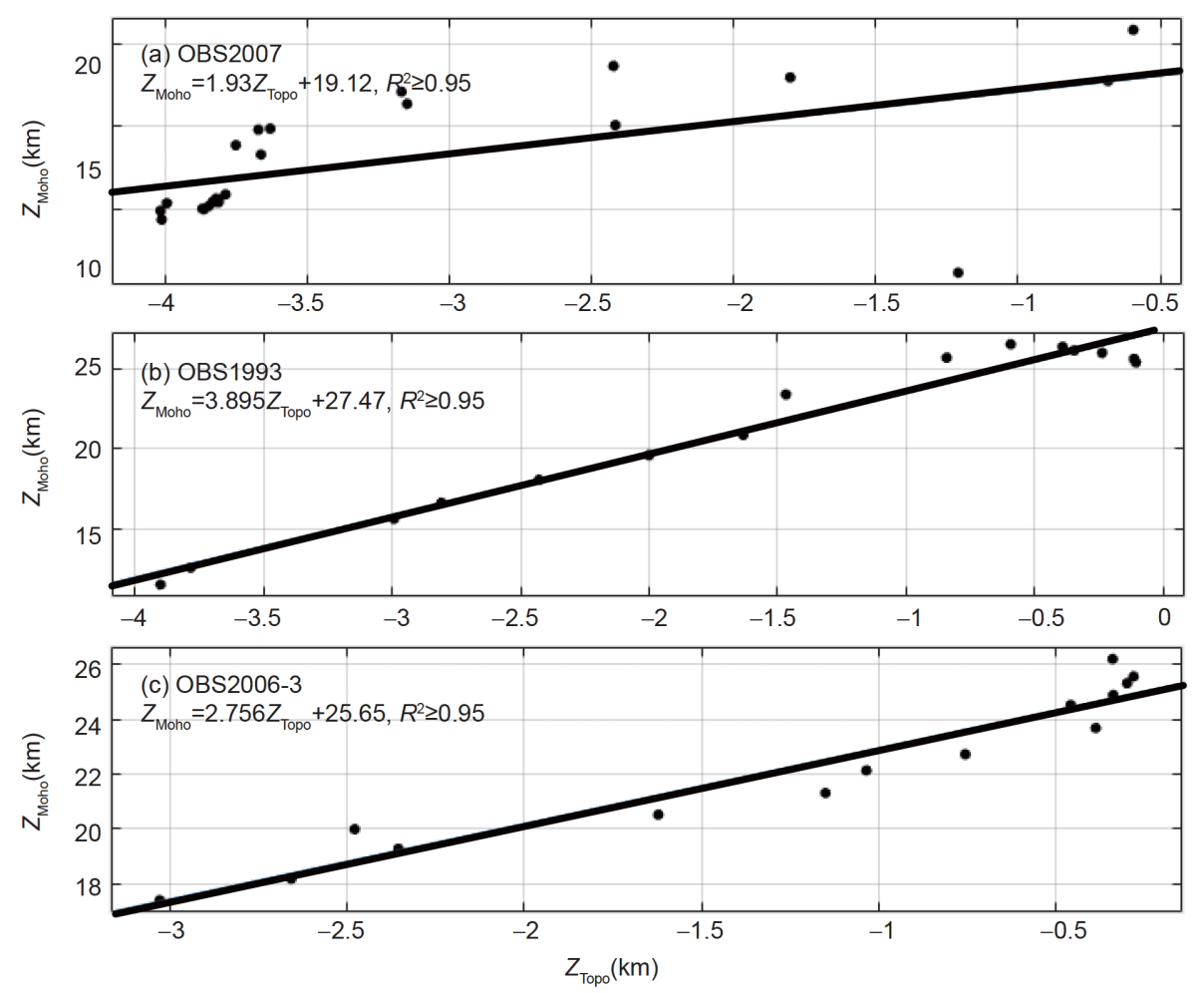

图 5 人工地震剖面OBS2007、OBS1993和OBS2006-3 的Moho和地形埋深的线性关系

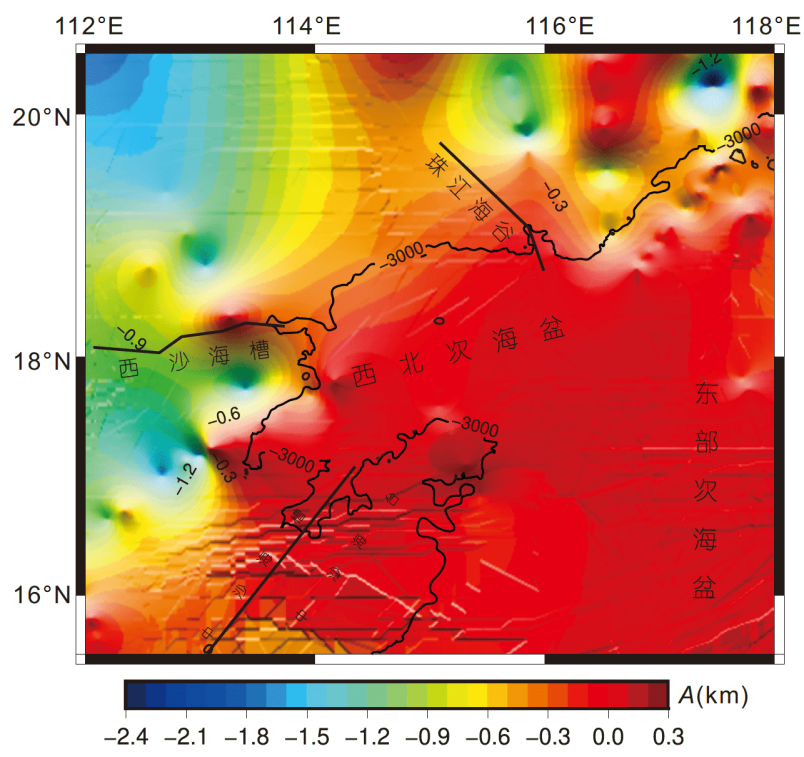

图 6 异常地形

黑色直线和折线代表西沙海槽、中沙海槽和珠江海谷

石圈地幔的平均SPT密度为 $3300 \mathrm{~kg} \mathrm{~m}^{-3}$ (张文涛, 2019). 假设海底温度为 $5^{\circ} \mathrm{C}$ (胡立天等, 2019), 岩石圈底部的

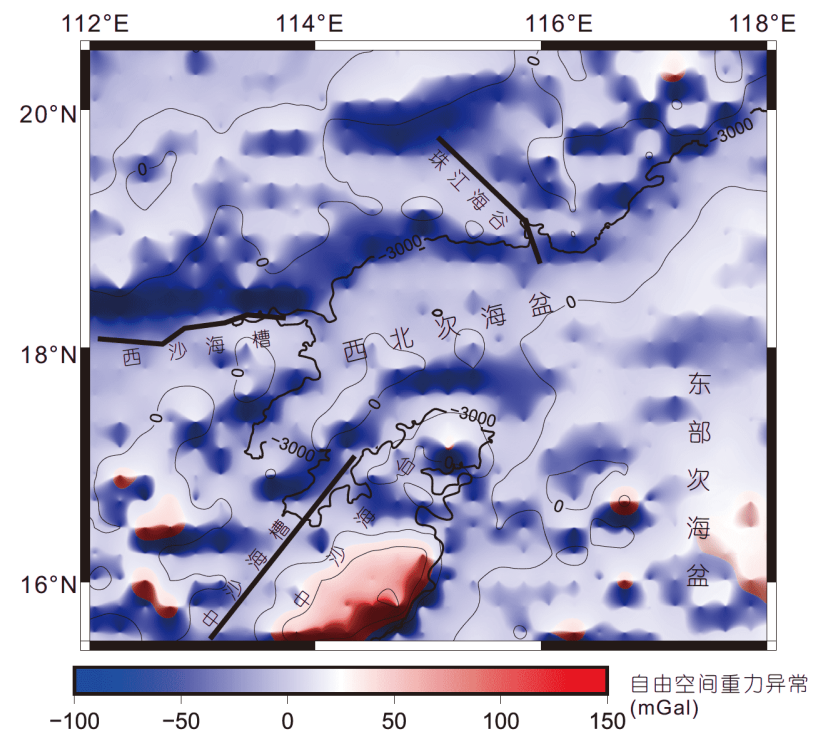

图 7 南海西北次海盆及其周边地区自由空间重力异常的 分布

黑色直线和折线代表西沙海槽、中沙海槽和珠江海谷, 黑色细曲线 代表自由空间重力异常值为零的等值线. 据Sandwell等(2014)

温度为 $1300^{\circ} \mathrm{C}$ (陈凌等, 2007$)$, 则平均岩石圈温度为 $648^{\circ} \mathrm{C}$, 那么原位岩石圈密度根据公式(2)可以写为 


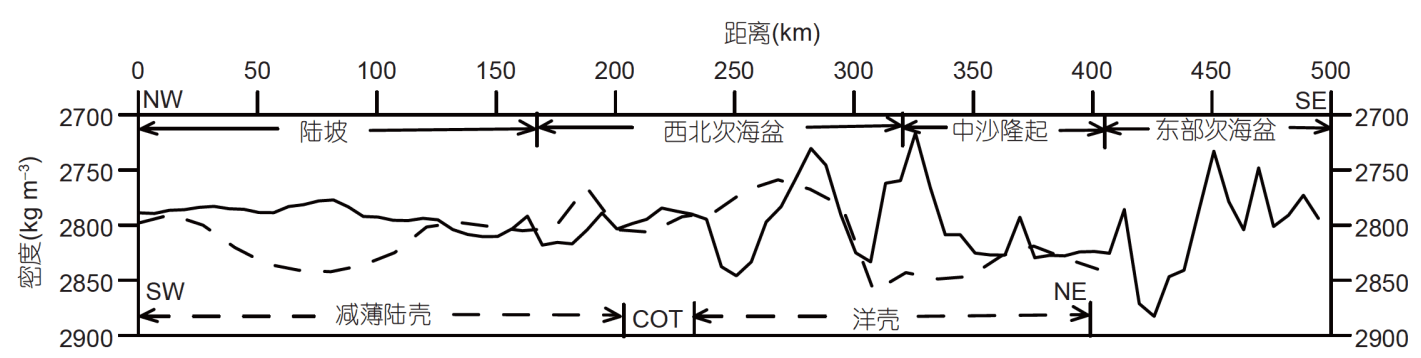

图 8 地震剖面OBS2006-1和OBS2006-2的地壳平均密度分布

实线表示OBS2006-1平均密度, 其平均值: $2798.38 \mathrm{~kg} \mathrm{~m}^{-3}$; 虚线表示OBS2006-2平均密度, 其平均值: $2805.44 \mathrm{~kg} \mathrm{~m}^{-3}$

$\rho_{0}=\rho_{0}(0)(1-648 \alpha)$.

结合公式(3) (5), 我们可以得到异常温度公式:

$\Delta T=95889 A /\left(3300 Z_{\mathrm{LAB}}-500 Z_{\mathrm{Moho}}\right)$.

另一方面，式(3)和(6)定义的温度异常 $\Delta T$ 是局部 的岩石圈的垂直平均温度变化相对于参考点 $A=0 \mathrm{~km}$ 处 的平均温度. 它意味着每个点的局部温度剖面与参考 温度剖面进行比较. 在海洋域中的参考点岩石圈厚度 为 $100 \mathrm{~km}$ (Artemieva, 2019), 我们根据陆坡、海槽和海 盆分别取 $80 、 60$ 和 $40 \mathrm{~km}$ (施小斌等，2000；姚伯初等， 2006; 胡立天等, 2019), 根据岩石圈垂直方向的异常 温度 $\Delta T$ 在参考点不同位置的变化, 可以计算参考点位 置的温度 $T_{\operatorname{Ref}}$ 和异常温度 $\Delta T($ Artemieva, 2019):

$$
\begin{aligned}
& T_{\operatorname{Ref}}=\left[648 Z_{\mathrm{LAB}}+1300\left(Z_{\mathrm{LAB}}^{\mathrm{Ref}}-Z_{\mathrm{LAB}}\right)\right] / Z_{\mathrm{LAB}}^{\mathrm{Ref}}, \\
& \Delta T=T_{\mathrm{Ref}}-648=652\left(1-Z_{\mathrm{LAB}} / Z_{\mathrm{Lab}}^{\mathrm{Ref}}\right),
\end{aligned}
$$

这里 $Z_{\mathrm{LAB}}^{\mathrm{Ref}}$ 是参考点的热岩石圈基底埋深.

结合公式(6)和(8), 可以得到异常地形和岩石圈厚 度的公式:

$A=\left(Z_{\mathrm{LAB}}^{\mathrm{Ref}}-Z_{\mathrm{LAB}}\right)\left(3300 Z_{\mathrm{LAB}}-500 Z_{\mathrm{Moho}}\right) / 14707$,

其中 $Z_{\mathrm{LAB}}$ 是热岩石圈厚度, $Z_{\mathrm{Moho}}$ 是Moho面的埋深．通 过求解方程(9)我们可以得到南海西北次海盆及其周 边地区的“热”岩石圈基底的埋深，因此本文提到的 $\mathrm{LAB}$ 是在实现重力均衡的前提下以温度来约束，即假 设达到均衡时的底界温度为 $1300^{\circ} \mathrm{C}$, 通过计算参考点 的异常温度变化得到异常地形 $(A)$ 和热岩石圈厚度 $\left(Z_{\mathrm{LAB}}\right)$ 的非线性公式，从而得到的热岩石圈基底埋深 (见图10).

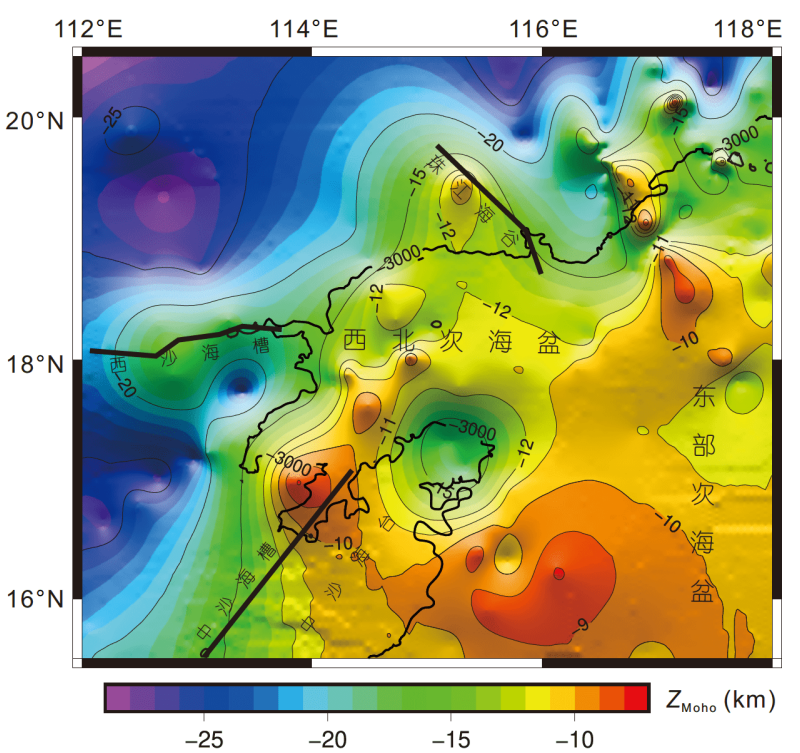

图 9 西北次海盆及其周边地区的Moho面的埋深 黑色曲线是Moho面的埋深 $10 、 15 、 20$ 和 $25 \mathrm{~km}$ 等深线, 黑色折线和 直线代表西沙海槽、中沙海槽和珠江海谷

\section{3 结果}

\section{1 地壳结构}

根据收集的OBS地震剖面和声纳浮标地震数据得 到的Moho面的埋深(图9), 我们发现该区域Moho面厚 度在 7 29km，在 $3000 \mathrm{~m}$ 水深的海盆范围内，基本在 $7 \sim 15 \mathrm{~km}$ ，之后迅速增加到陆坡范围15 25km. 西沙海 槽两侧的地壳结构呈现对称分布. 西北次海盆Moho面 埋深在10 15km, 局部地区少于 $10 \mathrm{~km}$. 中沙海槽和中 沙海台的地壳厚度分布具有阶梯性递减的分布特点, 与西北次海盆相邻区域小于 $10 \mathrm{~km}$ ，向西南延伸方向逐 渐增厚到 $17 \mathrm{~km}$. 东部次海盆从邻近西北次海盆的 10 12km向南逐渐减少到 $7 \mathrm{~km}$. 在珠江海谷西侧, 地壳 


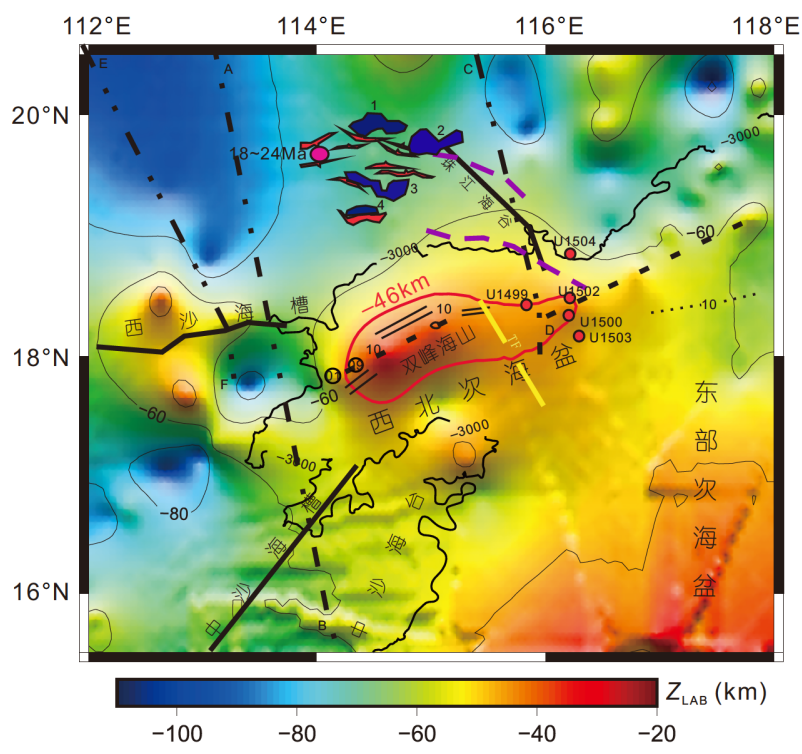

图 10 南海西北次海盆及其周边地区岩石圈的基底深度 图中黑色曲线和黑色粗曲线分别是岩石圈基底埋深和 $3000 \mathrm{~m}$ 水深等 深线，红色曲线是岩石圈基底埋深 $46 \mathrm{~km}$ 等深线; 黑色双线是西北次 海盆磁异常条带C10(Briais等, 1993; Li等, 2014, 2008); 紫色虚线是 断层的分布(Zhao等, 2020); 红色雁状代表断层(Wang 等, 2013); 蓝色 封闭区域代表一些凹陷，其中1代表白云西凹陷，2代表白云主凹陷， 4代表鹤山凹陷；红色圆点是IODP367、368、368x航次站位；粉色 椭圆表示定年的位置(Zhao等，2016); 有黑色外圈的数字01和09是 王强等(2020)认为的COT的位置; 黄色虚线TF代表转换断层(Larsen 等, 2018; Sun等, 2018); 黑色虚线是岩石圈基底峰脊的连线; 黑色双 点线是前人计算的“热”岩石圈基底厚度的剖面, 其中 $\mathrm{AB}$ 剖面来自胡 立天等(2019)的 $\mathrm{ABCD}$ 剖面(见图16), $\mathrm{CD}$ 和 $\mathrm{EF}$ 剖面对应施小斌等 (2000)的CD和EF剖面(见图17).

厚度小于 $20 \mathrm{~km}$, 向北也呈现出迅速减薄的分布特征.

\section{2 岩石圈结构与地表热流和地震层析成像之间 的对比}

通过热重力均衡得到的南海西北次海盆的岩石圈 基底的埋深范围在25 110km(见图10). 西沙海槽的南 北两侧具有明显的对称性，最薄处厚度小于 $40 \mathrm{~km}$. 中 沙海槽和中沙海台的岩石圈基底埋深从 $46 \mathrm{~km}$ 向西南 方向逐渐增厚到 $70 \mathrm{~km}$. 西北次海盆和东部次海盆的岩 石圈基底埋深小于 $60 \mathrm{~km}$. 西北次海盆磁异常条带识别 的洋中脊(Briais等，1993；Li等，2014，2008)恰好位于 $46 \mathrm{~km}$ 等值线内. 与西北次海盆内存在的 3 个岩石圈基 底的“峰脊”的分布完全一致. 其中U1500和U1502恰好 在最东侧岩石圈基底的“峰脊”的南、北两侧. 特别的, 珠江海谷西侧岩石圈基底埋深在60 80km，与断层和

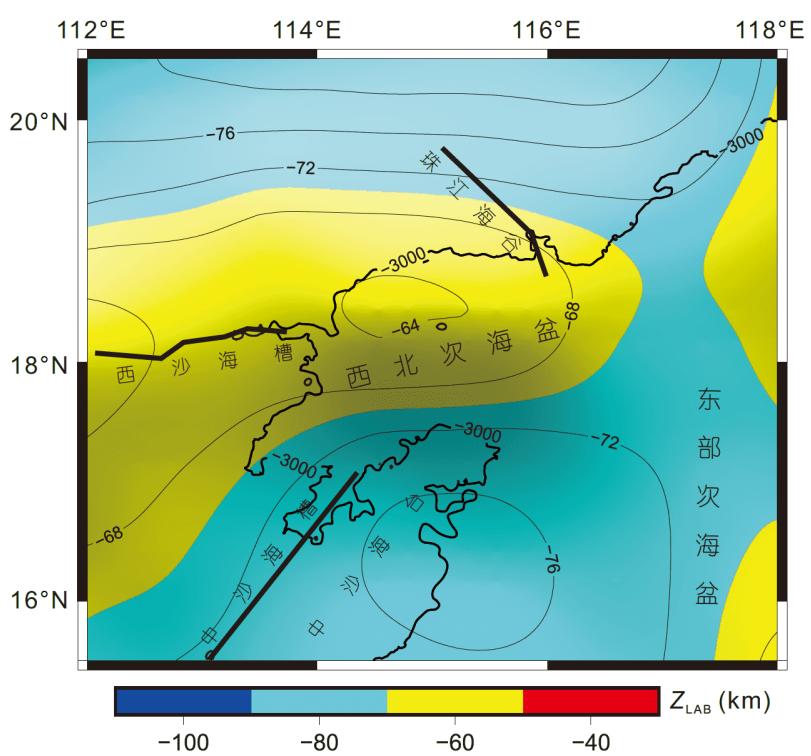

图 11 南海西北次海盆及其周边地区岩石圈基底深度 据Yu等(2017), 来自地震层析成像的结果(Tang和Zheng, 2013)

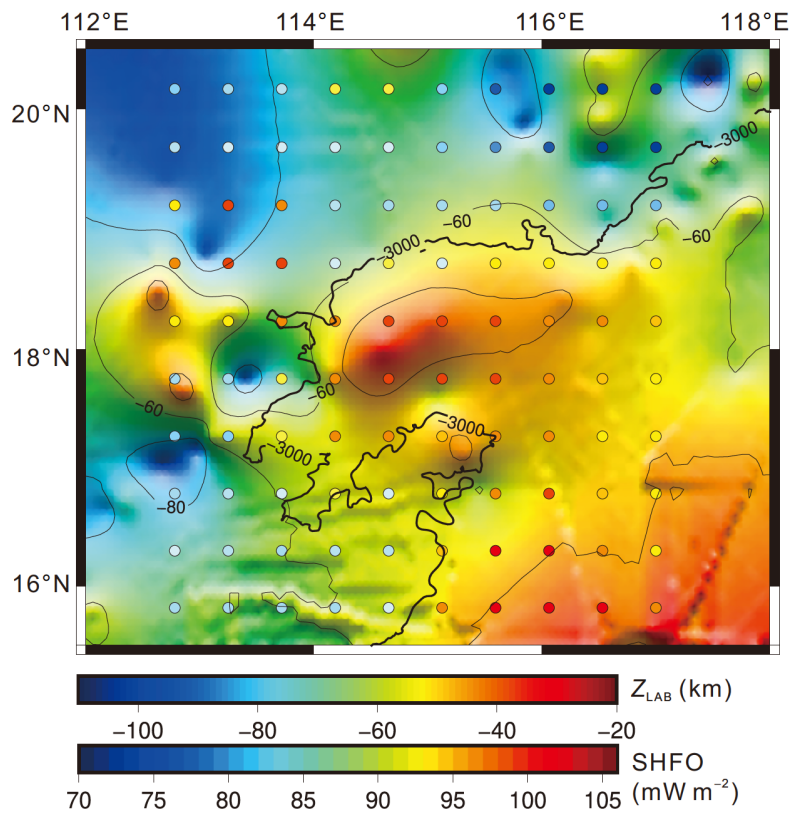

图 12 岩石圈基底埋深与地表热流观测值之间的对比 图中黑色曲线和黑色粗曲线分别是岩石圈基底埋深和 $3000 \mathrm{~m}$ 水深等 深线, 圆点代表表面热流观测值(SHFO)(米立军等, 2009; 徐行等, 2005, 2011，2012，2018)的插值点, 两个色标分别表示岩石圈基底埋 深深度和表面热流观测插值的变化范围

凹陷的分布位置(Zhao等, 2020; Wang等, 2013)具有很 好一致性. 整个研究区域的岩石圈基底的埋深基本小 于 $80 \mathrm{~km}$ 与地震层析成像的结果 $(62 \sim 84 \mathrm{~km}$ )接近(图 11 ; 


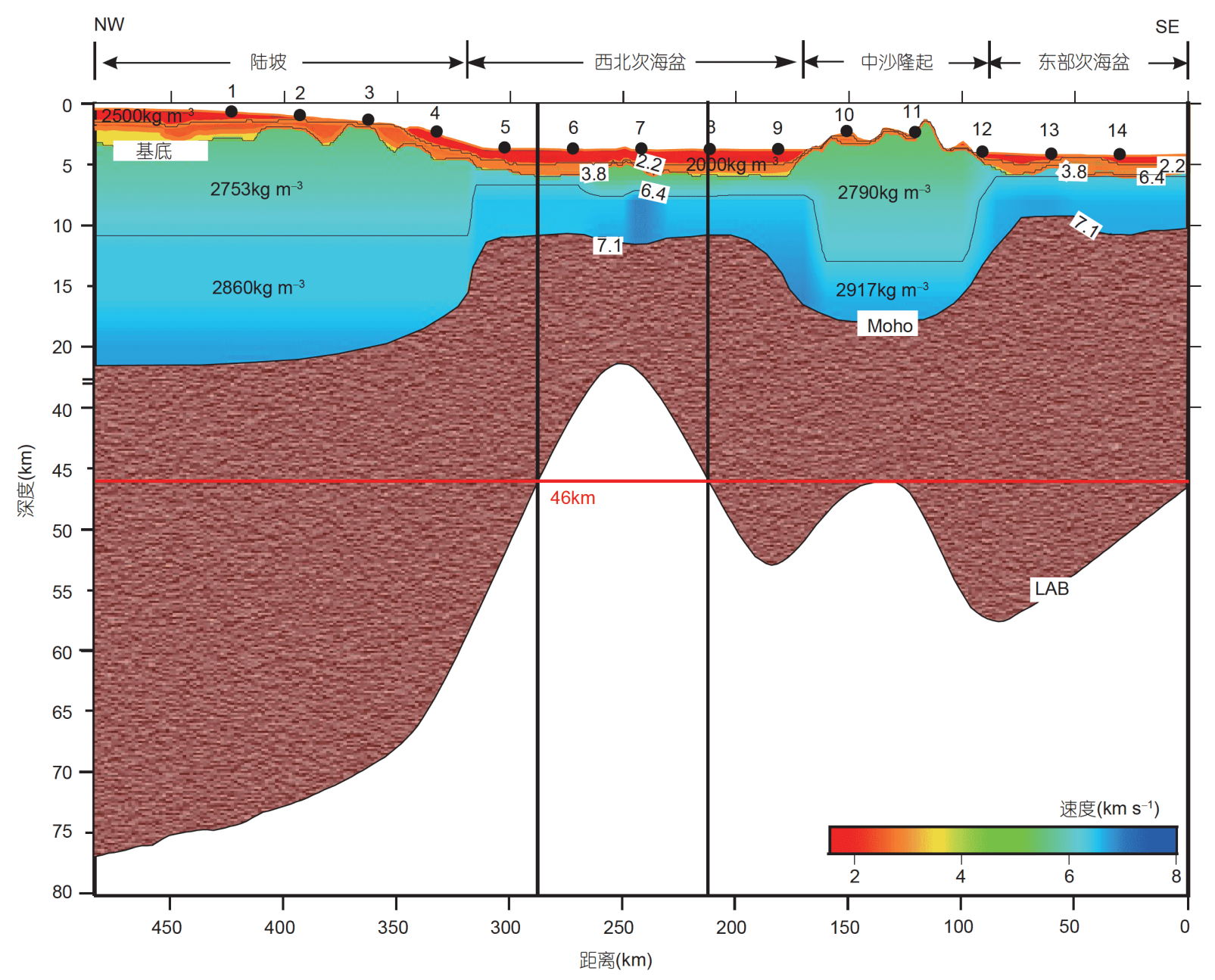

图 13 OBS2006-1测线的地壳速度结构和岩石圈深部构造的对比

地壳结构来自吴振利等(2011)和Huang等(2020). 红色实线代表本文计算的岩石圈埋深46km等深线,两条纵向黑色实线代表本文认为的成熟洋 壳边界

Tang和Zheng, 2013; Yu等, 2017), 但西沙海槽西侧、西 北次海盆、东部次海盆和珠江海谷岩石圈基底深度从 $80 \mathrm{~km}$ 逐渐减小到 $40 \mathrm{~km}$ 以内, 呈现出更为精细的岩石圈 结构. 本文的岩石圈基底埋深侧重于热岩石圈基底, 前 人结果认为热岩石圈基底相对地震层析成像得到的岩 石圈基底埋深浅(陈凌等, 2007).

为了更好的验证岩石圈基底埋深与表面热流之间 的响应关系，我们将岩石圈基底埋深与地表热流观测 值统一绘制于图12，除个别的点有出入外，基本与我 们计算的岩石圈基底埋深的变化格局一致，特别是西 北次海盆与东部次海盆吻合的非常好. 基于声纳浮 标、双船扩展剖面(ESP)、海底地震仪(OBS)、多波束 和海陆联测等地震调查数据反演的岩石圈基底埋深与
实测的海底热流的吻合, 我们认为重力均衡面在岩石 圈基底.

\section{3 剖面结构的分析}

为了对比剖面的地壳与岩石圈结构, 我们提取人 工地震剖面OBS2006-1(图13)、OBS2006-2(图14)和 OBH1996-4(图15)的地壳速度结构和热岩石圈基底 埋深.

穿过南海北部陆坡、西北次海盆和中沙海台的 OBS2006-1测线的岩石圈结构显示(图13), 热重力均衡 得到的岩石圈基底埋深的范围约30 77km，位于地壳 下方横向距离约 $0 \sim 100 、 190 \sim 250$ 和 $250 \sim 500 \mathrm{~km}$ 的区 域, 地壳厚度与热岩石圈的厚度同步迅速减薄, 体现了 


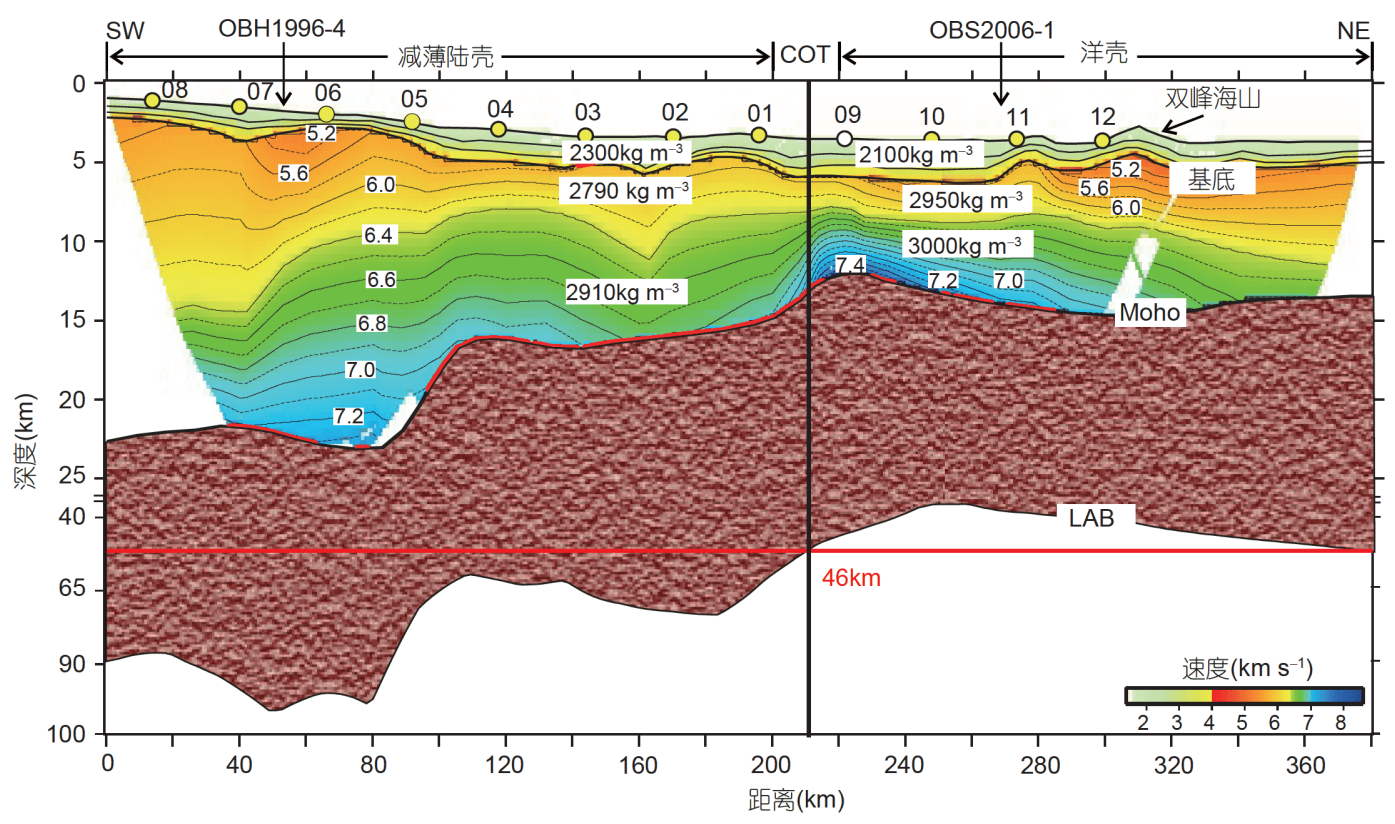

图 14 OBS2006-2测线的地壳速度结构和岩石圈深部构造的对比

地壳结构据王强等(2020), 红色横向实线代表本文计算的岩石圈埋深46km等深线, 黑色纵向实线代表本文认为的成熟洋壳边界

地壳和岩石圈伸展的一致性，而位于中沙隆起地区的 下方, 地壳几乎没有伸展变形, 但有明显的减薄, 而热 岩石圈的厚度明显减薄, 对比陆坡区和海盆区, 即在横 向距离250 500和190 250km的区域, 岩石圈减薄呈现 了非均匀性，可能与陆块、微陆块形成过程中产生的 岩石圈基底的物质活动有关.

横穿西北次海盆的人工地震剖面OBS2006-2测线 的地壳和热岩石圈结构显示(图14), 热重力均衡得到 的岩石圈基底埋深范围在 $40 \sim 97 \mathrm{~km}$ ，位于地壳 $80 \mathrm{~km}$ 和 洋陆转换带COT(continent-ocean transition)下方 $180 \mathrm{~km}$ 的位置处, 地壳厚度与热岩石圈的厚度同步迅速减薄, 体现了地壳和岩石圈伸展的一致性. 而岩石圈最薄区 域位于等值线 $46 \mathrm{~km}$ 以内，恰好位于王强等 $(2020)$ 的 COT内 $210 \mathrm{~km}$ 的位置, 并与磁异常条带识别的洋中脊 C10(Briais等, 1993)位置一致, 是我们认为的成熟洋壳 区域. 双峰海山下方地壳厚度的增加应与扩展后期岩 浆活动有关(Yan等, 2001; 吴振利等, 2011; Huang等, 2020).

穿过西沙海槽的OBH1996-4测线的地壳和热岩石 圈结构显示出完美对称结构(图15), 热重力岩石圈基 底埋深的范围在 $46 \sim 80 \mathrm{~km}$, 在剖面中大约 $(0 \pm 100) \mathrm{km}$ 偏 移距处开始隆起, 在大约 $(0 \pm 50) \mathrm{km}$ 处岩石圈基底埋深
达到最浅，而在 $(0 \pm 50) \mathrm{km}$ 以内的裂谷中心，岩石圈基 底出现弧形凹陷.

\section{4 讨论}

\section{1 寻找洋壳及最窄洋陆转换带的重要依据}

首先, 在西北次海盆中, 热重力均衡得到的岩石圈 基底埋深的最浅区域(46km的等深线)的分布形态与洋 中脊磁异常条带(C10)完全一致(图10). 其次, 国际大洋 钻探IODP站位U1500和U1502(Sun等，2018)恰好位于 热岩石圈基底埋深较浅的“峰脊”的两侧, 热岩石圈基 底埋深 $46 \mathrm{~km}$ 的等深线上，分别钻遇了超过 $120 \mathrm{~m}$ 的较 新鲜洋中脊玄武岩(MORB)和 $180 \mathrm{~m}$ 左右的蚀变玄武 岩. 而偏离岩石圈基底埋深较浅的“峰脊”的站位 U1499也位于岩石圈基底埋深 $46 \mathrm{~km}$ 的等深线上，但未 出现洋壳成分. 与此同时, 岩石圈基底埋深 $46 \mathrm{~km}$ 的等 深线的最西端也与王强等(2020)根据广角折射走时模 拟结果划分的西北次海盆的 COT范围(站位01和09之 间, 见图10和图14)非常接近. 综上所述, 我们认为西北 次海盆成熟洋壳范围应界定在热岩石圈基底埋深 $46 \mathrm{~km}$ 等值线以内(图10), 该范围与前人的COT结果相 比明显要小(Cameselle等, 2017; 张涛等, 2012). 较窄 


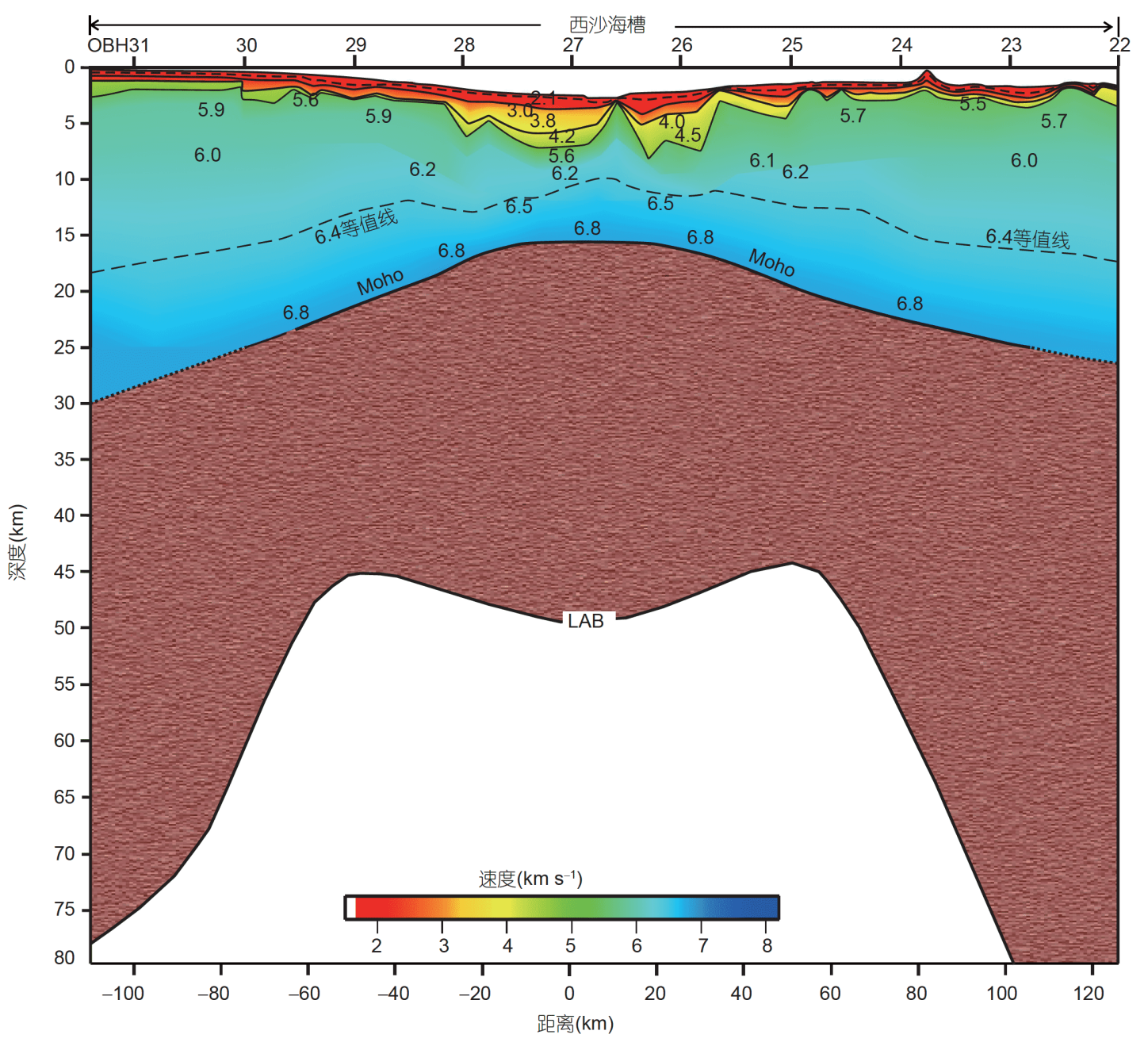

图 15 OBH1996-4测线的地壳速度结构和岩石圈深部构造的对比

地壳结构据Qiu等(2001)

的COT范围支持该区具有快速的洋陆转换过程(Larsen等，2018). 另外，我们用黑色虚线连接了岩石圈基 底“峰脊”, 发现东、西两部分(图10的两条黑色虚线)被 转换断层 $\mathrm{TF}$ (图1和图10中黄色虚线)所分割. 我们认为 西北次海盆洋中脊的深部热结构和东部次海盆北端深 部热结构呈现出分段不同走向的展布，与南海海盆北 端的地形分布形态一致，体现出深部构造和热状态与 地表构造的响应关系.

\section{2 热岩石圈深部结构与浅部构造单元的耦合关 系}

南海西北次海盆及其周边地区岩浆活动强烈，从 洋中脊(包括东部次海盆)到西沙海槽和中沙海槽，再
到珠江海谷西侧都有后期的岩浆活动。定年结果显示 西北次海盆扩张过程较短(约32 25Ma), 双峰海山是 在西北次海盆扩张停止 $2 \mathrm{Myr}$ 后岩浆侵入活动形成 $(\mathrm{Li}$ 等，2015a，2015b)，与珠江海谷西侧的岩浆活动时间 18 24Ma(Zhao等, 2016)一致. 这种扩张后期岩浆活动 导致西北次海盆具有较高的海底热流值(张健和汪集 昒, 2000; 徐行等, 2005, 2011, 2012, 2018). 从热岩石圈 基底埋深的分布来看，这些后期岩浆活动以及高热流 区基本对应着明显的热岩石圈减薄. 西北次海盆演化 过程中形成的热岩石圈结构形态，可能为后期来自深 部的热物质提供了上升空间.

在西北次海盆的北部陆缘, 珠江海谷西侧, 减薄的 热岩石圈范围与Zhao等(2020)和Wang等(2013)中的断 


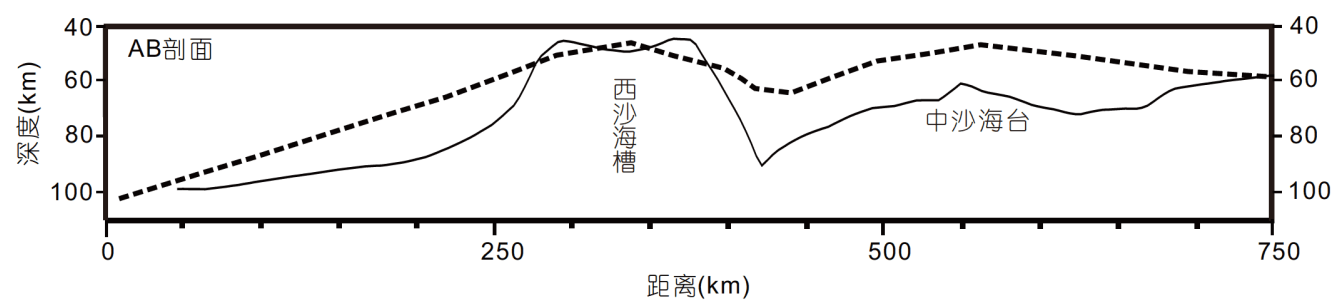

图 16 不同方法得到的岩石圈基底深度的对比

黑色虚线是胡立天等(2019)计算的 $\mathrm{ABCD}$ 剖面的岩石圈基底深度(本文取作 $\mathrm{AB}$ 剖面，位置见图 10 黑色双点线)，黑色实线是本文计算的同一剖 面的岩石圈基底深度

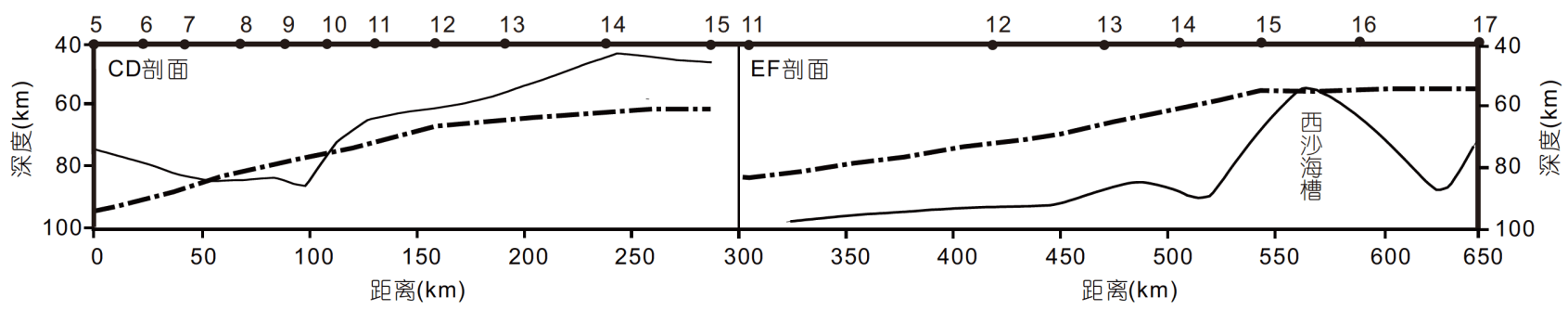

图 17 不同方法得到的岩石圈基底深度的对比

黑色虚点线是施小斌等(2000)计算的 $\mathrm{CD}$ 剖面(左)和 $\mathrm{EF}$ (右)剖面(位置见图10黑色双点线)的岩石圈基底深度, 黑色点和数字表示站位, 黑色实线 是本文计算的对应CD剖面和EF剖面的岩石圈基底深度

层和凹陷的分布一致，说明该区的断层和凹陷的发育 与岩石圈深部构造和热状态可能具有同源性. 但珠江 海谷的深部结构与其浅部走向和地形形态分布明显不 一致，反映了后期构造运动对浅部断层和凹陷的改造， 可能跟海底滑坡和沿断裂带的岩浆活动有关(Zhao等, 2016). 另外，南海北部陆缘伸展作用是在中生代洋-陆 碰撞的应力松弛背景下进行的，前期挤压构造以及与 挤压方向共轭的断裂作用，同样在该区留下了继承性 的浅部地质遗迹，可能也是其浅部地形和深部构造走 向不一致的原因(Wang等，2020; Ye等，2020). 在此区 域, 我们计算的热岩石圈基底埋深与前人的结果(施小 斌等，2000; 胡立天等，2019)总体趋势一致(见图16和 17), 特别是在西沙海槽和中沙海台, 但也表现出一些 不同细节上的结构信息，可能与热重力均衡在岩石圈 拉张减薄过程中的非均质地区、断层或者凹陷的分布 有不同的响应关系.

西沙海槽作为西北次海盆向西的延伸，其地壳结 构表现为一条夭折的裂谷特征(Qiu等，2001). 本研究 结果显示，与西沙海槽明显呈对称分布的海底地形、 Moho埋深和地壳结构相一致, 其热重力均衡得到的岩 石圈底界形态和厚度也表现为明显对称性，证实其为
陆缘伸展作用下的大陆裂谷. 西沙海槽中心岩石圈厚 度的增加, 可能与大陆伸展后期热重力均衡作用以及 后期表现出热物质活动有关.

中沙海台在地壳结构上表现为一个坚硬陆块, 其 地壳结构明显有别于两侧海盆和西侧裂谷. 其北侧因 位于东部次海盆洋中脊跳跃的西端，受海盆扩张影响 其地形和基底形态上表现为一系列火山脊构造. 相应 地, 中沙海台下方岩石圈具有减薄特征, 表现为热岩 石圈底界的上隆，反映了坚硬地块下仍存在来自岩石 圈深部物质的强烈改造, 保留了与坚硬地块裂解以及 后期岩浆作用改造有关的深部动力信息. 因此，中沙 地块的裂离演化过程可能同时受到海盆扩张脊向大陆 的推进以及陆缘伸展的双重作用，其深部动力学机制 究竟如何仍需要做进一步的模拟工作.

\section{5 结论}

通过收集和整理南海西北次海盆及其周边地区的 OBS地震剖面、声纳浮标、双船扩展剖面(ESP)、多 道地震等地震数据, 提取地形和Moho面的埋深. 根据 热重力均衡得到的岩石圈基底埋深. 并得到以下结论: 
(1) 热岩石圈基底在西沙海槽的南、北两侧具有 明显的对称性，其热状态与深部构造是西沙海槽的 南、北对称地貌的控制因素. 中沙海槽和中沙海台的 热岩石圈基底埋深从 $46 \mathrm{~km}$ 向西南方向增厚到 $70 \mathrm{~km}$, 特别是中沙海台南、北端呈现出热岩石圈结构的非均 质性，可能与陆块、微陆块区固有的岩石圈结构差异 有关.

(2) 西北次海盆北部陆缘, 特别是珠江海谷西侧区 域, 热岩石圈厚度范围在60 80km, 与前人识别的部分 断层和凹陷的位置一致，说明该区域岩石圈厚度的减 薄与断层和凹陷的分布有关，体现了热重力均衡在有 断层和凹陷分布区域的不同响应关系.

（3）西北次海盆和东部次海盆岩石圈基底埋深小 于 $60 \mathrm{~km}$, 最浅埋深小于 $46 \mathrm{~km}$. 在西北次海盆洋壳内存 在3个小的热岩石圈基底的“峰脊”, 与西北次海盆的洋 中脊(磁异常条带C10)和地形的分布形态一致，同时根 据IODP站位和人工地震双程走时确定的洋壳和陆壳 的范围，我们认为热岩石圈基底埋深 $46 \mathrm{~km}$ 的等深线是 西北次海盆的成熟洋壳区域.

（4）南海西北次海盆及其周边地区不同构造单元 与深部热岩石圈构造和热状态紧密相关. 西沙海槽、 中沙海槽和中沙海台的形成都有来自深部的构造作 用, 珠江海谷的形成也与Moho面的埋深(图4)和热岩石 圈基底的构造(图6)有一定的关系. 但与地形分布明显 不一致, 可能与海底滑坡和断层上岩浆活动有关.

致谢感谢中国科学院南海海洋研究所丘学林研究员和 赵明辉研究员在论文撰写和修改过程中给予的指导和帮 助。三位若名评审专家和责任编委刘丽军研究员的宝贵 意见和建设性建议, 大大提升了文章学术水平, 在此一并 致谢.

\section{参考文献}

敖威, 赵明辉, 丘学林, 阮爱国, 李家彪. 2012. 南海西北次海盆及其 邻区地壳结构和构造意义. 地球科学: 中国地质大学学报，37 $779-790$

陈凌, 朱日祥, 王涛. 2007. 大陆岩石圈研究进展. 地学前缘, 14: 5875

丁巍伟, 黎明碧, 赵例红, 阮爱国, 吴振利. 2009. 南海西北次海盆新 生代构造-沉积特征及伸展模式探讨. 地学前缘, 4: 147-156

郝天珧, 徐亚, 孙福利, 李志伟, 胥䝠, 雷受旻, 杨金玉. 2011. 南海共 轭大陆边缘构造属性的综合地球物理研究. 地球物理学报, 54 :
$3098-3116$

黄忠贤, 胥卧. 2011. 南海及邻近地区面波层析成像和 $\mathrm{S}$ 波速度结构。 地球物理学报, 54: 3089-3097

黄海波, 丘学林, 徐辉龙, 赵明辉, 郝天姚, 胥卧, 李家彪. 2011. 南海 西沙地块岛屿地震观测和海陆联测初步结果. 地球物理学报, 54 : $3161-3170$

胡立天, 张培震, 郝天珧, 徐亚. 2019. 南海西南次海盆岩石圈结构及 其地质意义. 地球物理学报, 62: 3464-3481

姜绍仁, 周效中, 黄慈流, 夏勘原, 刘帝光, 黄志明. 1990a. 南海曾母 盆地地质构造特征及演化历史. 海洋地质与第四纪地质, 10: 2536

姜绍仁, 周效中, 黄慈流, 夏勘原, 刘帝光. 1990b. 曾母盆地构造层特 征. 热带海洋学报, 9: 23-30

姜绍仁, 周效中. 1993. 南沙群岛海域构造地层及构造运动. 热带海 洋学报, 12: 55-62

刘赛君，曾钢平，丘学林，符干, 吴世敏，叶三余，陈金海, Flueh E. 2011. 海南岛西南海域地壳剖面海陆联合探测研究. 地球物理学 进展, 3: 922-933

刘金萍，阎贫. 2003. 南海西南次海盆声纳浮标地震测深资料研究. 海洋科学, 27: 35-40

李振五. 1984. 南海中部和北部地壳性质的探讨. 地球物理学报, 27: 153-166

米立军, 袁玉松, 张功成, 胡圣标, 何丽娟, 杨树春. 2009. 南海北部深 水区地热特征及其成因. 石油学报, 30: 27-30

丘学林, 赵明辉, 敖威, 吕川川, 郝天珧, 游庆瑜, 阮爱国, 李家彪. 2011. 南海西南次海盆与南沙地块的OBS探测和地壳结构. 地球 物理学报, 54: 3117-3128

邱禁翔. 2010. 南中国海北部大陆边缘之海陆地过渡带的P波速度模 式. 博士学位论文. 基隆: “国立”台湾海洋大学

任建业, 庞雄, 于鹏, 雷超, 罗盼. 2018. 南海北部陆缘深水-超深水盆 地成因机制分析. 地球物理学报, 61: 4901-4920

阮爱国, 牛雄伟, 丘学林, 李家彪, 吴振利, 赵明辉, 卫小冬. 2011. 穿 越南沙礼乐滩的海底地震仪广角地震试验. 地球物理学报, 54 : 3139-3149

施小斌, 周蒂, 张毅祥. 2000. 南海北部陆缘岩石圈热-流变结构. 科学 通报, 45: 1660-1665

吴世敏, 周蒂, 丘学林, 叶三余, Flueh E, 杨计海. 2001. 南海西北部莺 歌海盆地低速层的特征及其成因探讨. 热带海洋学报, 20: 8-14

吴振利, 李家彪, 阮爱国, 丁巍伟, 李湘云, 丘学林, 赵明辉, 郭兴伟. 2008. 南海中北部地壳深部结构探测新进展. 华南地震, 28: 2128

吴振利, 阮爱国, 李家彪, 楼海, 丁巍伟, 牛雄伟, 李细兵. 2011. 南海 西北次海盆地壳结构: 海底广角地震实验结果. 中国科学: 地球 科学, 41: 1463-1476

汪品先. 2019. 大洋钻探与中国的海洋地质. 海洋地质与第四纪地质, 39: $7-14$ 
王强, 赵明辉, 张浩宇, 张佳政, 贺恩远, 袁野, 丘学林. 2020. 基于重 处理数据的南海西北次海盆地壳速度结构. 中国科学: 地球科学, 50: $1553-1568$

夏少红, 郭兴伟, 黄海波, 丘学林. 2014. 南海岩石层及边界构造的地 球物理特征. 地球物理学报, 57: 3957-3967

徐行, 陆敬安, 罗贤虎, 耿雪樵, 张志刚. 2005. 南海北部海底热流测 量及分析. 地球物理学进展, 20: 562-565

徐行, 李亚敏, 罗贤虎, 施小斌, 杨小秋. 2012. 南海北部陆坡水合物 勘探区典型站位不同类型热流对比. 地球物理学报，55：9981006

徐行, 何家雄, 何丽娟, 龚晓峰. 2011. 南海北部与南部新生代沉积盆 地热流分布与油气运聚富集关系. 海洋地质与第四纪地质, 31 : 99-108

徐行, 王先庆, 彭登, 姚永坚, 姚伯初, 万志峰. 2018. 南海西北次海盆 及其邻区的地热流特征与研究. 地球科学, 43: 3391-3398

徐辉龙, 夏少红, 孙金龙, 丘学林, 曹敬贺. 2012. 南海北部海陆联合 深地震探测及其地质学意义. 热带海洋学报, 31: 21-27

姚伯初, 万玲, 何丽娟, 曾维军, 汪集昒, 李唐根, 杨小强, 吴能友, 张 锡林, 邹和平, 朱本铎. 2006. 中国南海海域岩石圈三维结构及演 化. 北京: 地质出版社

阎贫, 刘海龄. 2002. 南海北部陆缘地壳结构探测结果分析. 热带海 洋学报. 21: 1-12

赵明辉, 丘学林, 夏嵁原, 谢剑波, 叶春明. 2004. 南海东北部海陆联 测地震数据处理及初步结果. 热带海洋学报, 23: 58-63

赵明辉, 丘学林, 夏少红, 王平, 夏戴原. 2007. 南海东北部三分量海 底地震仪记录中横波的识别和分析. 自然科学进展, 17: 15161523

周效中, 姜绍仁, 叶秀开. 1993. 南沙群岛海域地质与油气远景. 中国 海上油气, (5): 1-7

张健, 汪集昒. 2000. 南海北部大陆边缘深部地热特征. 科学通报, 45: 1095-1100

张文涛. 2019. 南海海盆深部岩石圈结构的地球物理-岩石学自洽模 型. 硕士学位论文. 广州: 中国科学院南海海洋研究所

张涛, 高金耀, 李家彪, 吴招才, 吴振利, 赵俐红, 杨春国, 沈中延, 周 志远. 2012. 南海西北次海盆的磁条带重追踪及洋中脊分段性. 地球物理学报, 55: 3163-3172

Artemieva I M. 2019. Lithosphere structure in Europe from thermal isostasy. Earth-Sci Rev, 188: 454-468

Briais A, Patriat P, Tapponnier P. 1993. Updated interpretation of magnetic anomalies and seafloor spreading stages in the South China Sea: Implications for the Tertiary tectonics of Southeast Asia. J Geophys Res, 98: 6299-6328

Childress L, and the Expedition 368X Scientists, 2019. Expedition 368X Preliminary Report: South China Sea Rifted Margin. International Ocean DiscoveryProgram, https://doi.org/10.14379/ iodp.pr.368X.2019
Cameselle A L, Ranero C R, Franke D, Barckhausen U. 2017. The continent-ocean transition on the northwestern South China Sea. Basin Res, 29: 73-95

Deschamps F, Trampert J, Snieder R. 2002. Anomalies of temperature and iron in the uppermost mantle inferred from gravity data and tomographic models. Phys Earth Planet Inter, 129: 245-264

Ding W, Li M, Zhao L, Ruan A, Wu Z. 2011. Cenozoic tectonosedimentary characteristics and extension model of the Northwest Sub-basin, South China Sea. Geosci Front, 2: 509-517

Ding W, Sun Z, Dadd K, Fang Y, Li J. 2018. Structures within the oceanic crust of the central South China Sea basin and their implications for oceanic accretionary processes. Earth Planet Sci Lett, 488: 115-125

Ding W, Li J. 2016. Propagated rifting in the Southwest Sub-basin, South China Sea: Insights from analogue modelling. J Geodyn, 100: $71-86$

Eakin D H, McIntosh K D, Van Avendonk H J A, Lavier L, Lester R, Liu C S, Lee C S. 2014. Crustal-scale seismic profiles across the Manila subduction zone: The transition from intraoceanic subduction to incipient collision. J Geophys Res-Solid Earth, 119: 1-17

Franke D, Barckhausen U, Heyde I, Tingay M, Ramli N. 2008. Seismic images of a collision zone offshore NW Sabah/Borneo. Mar Pet Geol, 25: 606-624

Gao J, Wu S, McIntosh K, Mi L, Liu Z, Spence G. 2016. Crustal structure and extension mode in the northwestern margin of the South China Sea. Geochem Geophys Geosyst, 17: 2143-2167

Hoggard M J, White N, Al-Attar D. 2016. Global dynamic topography observations reveal limited influence of large-scale mantle flow. Nat Geosci, 9: 456-463

Huang H, He E, Qiu X, Guo X, Fan J, Zhang X. 2020. Insights about the structure and development of Zhongsha Bank in the South China Sea from integrated geophysical modelling. Int Geol Rev, 62: 10701080

Jian Z, Larsen H C, Alvarez Zarikian C A, and the Expedition 368 Scientists. 2018. Expedition 368 Preliminary Report: South China Sea Rifted Margin. International Ocean Discovery Program. https:// doi.org/10.14379/iodp.pr.368.2018

Lithgow-Bertelloni C, Gurnis M. 1997. Cenozoic subsidence and uplift of continents from time-varying dynamic topography. Geology, 25: 735-738

Larsen H C, Mohn G, Nirrengarten M, Sun Z, Stock J, Jian Z, Klaus A, Alvarez-Zarikian C A, Boaga J, Bowden S A, Briais A, Chen Y, Cukur D, Dadd K, Ding W, Dorais M, Ferré E C, Ferreira F, Furusawa A, Gewecke A, Hinojosa J, Höfig T W, Hsiung K H, Huang B, Huang E, Huang X L, Jiang S, Jin H, Johnson B G, Kurzawski R M, Lei C, Li B, Li L, Li Y, Lin J, Liu C, Liu C, Liu Z, 
Luna A J, Lupi C, McCarthy A, Ningthoujam L, Osono N, Peate D W, Persaud P, Qiu N, Robinson C, Satolli S, Sauermilch I, Schindlbeck J C, Skinner S, Straub S, Su X, Su C, Tian L, van der Zwan F M, Wan S, Wu H, Xiang R, Yadav R, Yi L, Yu P S, Zhang C, Zhang J, Zhang Y, Zhao N, Zhong G, Zhong L. 2018. Rapid transition from continental breakup to igneous oceanic crust in the South China Sea. Nat Geosci, 11: 782-789

Li C F, Zhou Z, Li J, Chen B, Geng J. 2008. Magnetic zoning and seismic structure of the South China Sea ocean basin. Mar Geophys Res, 29: 223-238

Li C F, Xu X, Lin J, Sun Z, Zhu J, Yao Y, Zhao X, Liu Q, Kulhanek D K, Wang J, Song T, Zhao J, Qiu N, Guan Y, Zhou Z, Williams T, Bao R, Briais A, Brown E A, Chen Y, Clift P D, Colwell F S, Dadd K A, Ding W, Almeida I H, Huang X L, Hyun S, Jiang T, Koppers A A P, Li Q, Liu C, Liu Z, Nagai R H, Peleo-Alampay A, Su X, Tejada M L G, Trinh H S, Yeh Y C, Zhang C, Zhang F, Zhang G L. 2014. Ages and magnetic structures of the South China Sea constrained by deep tow magnetic surveys and IODP Expedition 349. Geochem Geophys Geosyst, 15: 4958-4983

Li C F, Li J, Ding W, Franke D, Yao Y, Shi H, Pang X, Cao Y, Lin J, Kulhanek D K, Williams T, Bao R, Briais A, Brown E A, Chen Y, Clift P D, Colwell F S, Dadd K A, Hernández-Almeida I, Huang X L, Hyun S, Jiang T, Koppers A A P, Li Q, Liu C, Liu Q, Liu Z, Nagai R H, Peleo-Alampay A, Su X, Sun Z, Tejada M L G, Trinh H S, Yeh Y C, Zhang C, Zhang F, Zhang G L, Zhao X. 2015a. Seismic stratigraphy of the central South China Sea basin and implications for neotectonics. J Geophys Res, 120: 1377-1399

Li C F, Lin J, Kulhanek D K, the Expedition 349 Scientists. 2015b. Proceedings of the International Ocean Discovery Program. South China Sea Tectonics. vol. 349. College Station (International Ocean Discovery Program), TX

Liu L. 2015. The ups and downs of North America: Evaluating the role of mantle dynamic topography since the Mesozoic. Rev Geophys, 53: $1022-1049$

Liu L. 2020. The elusive mantle dynamic topography. Sci China Earth Sci, 63: 312-314

McIntosh K, Nakamura Y, Wang T K, Shih R C, Chen A, Liu C S. 2005. Crustal-scale seismic profiles across Taiwan and the western Philippine Sea. Tectonophysics, 401: 23-54

Nissen S S, Hayes D E, Buhl P, Diebold J, Bochu Y, Zeng W, Chen Y. 1995. Deep penetration seismic soundings across the northern margin of the South China Sea. J Geophys Res, 100: 22407-22433

Pari G, Peltier W R. 2000. Subcontinental mantle dynamics: A further analysis based on the joint constraints of dynamic surface topography and free-air graviy. J Geophys Res, 105: 5635-5662

Pichot T, Delescluse M, Chamot-Rooke N, Pubellier M, Qiu Y,
Meresse F, Sun G, Savva D, Wong K P, Watremez L, Auxiètre J L. 2014. Deep crustal structure of the conjugate margins of the SW South China Sea from wide-angle refraction seismic data. Mar Pet Geol, 58: 627-643

Qiu X, Ye S, Wu S, Shi X, Zhou D, Xia K, Flueh E R. 2001. Crustal structure across the Xisha trough, northwestern South China Sea. Tectonophysics, 341: 179-193

Steinberger B. 2016. Topography caused by mantle density variations: Observation-based estimates and models derived from tomography and lithosphere thickness. Geophys J Int, 205: 604-621

Sun Z, Zhong Z, Keep M, Zhou D, Cai D, Li X, Wu S, Jiang J. 2009. $3 \mathrm{D}$ analogue modeling of the South China Sea: A discussion on breakup pattern. J Asian Earth Sci, 34: 544-556

Sun Z, Jian Z, Stock J M, Larsen H C, Klaus A, Alvarez Zarikian C A, and the Expedition 367/368 Scientists. 2018. South China Sea Rifted Margin. Proceedings of the International Ocean Discovery Program, 367/368: College Station, TX. International Ocean Discovery Program, https://doi.org/10.14379/iodp.proc. 367368.2018

Sandwell D T, Müller R D, Smith W H F, Garcia E, Francis R. 2014. New global marine gravity model from CryoSat-2 and Jason-1 reveals buried tectonic structure. Science, 346: 65-67

Schutt D L, Lesher C E. 2006. Effects of melt depletion on the density and seismic velocity of garnet and spinel lherzolite. J Geophys Res, 111: B05401

Simmons N A, Forte A M, Grand S P. 2009. Joint seismic, geodynamic and mineral physical constraints on three-dimensional mantle heterogeneity: Implications for the relative importance of thermal versus compositional heterogeneity. Geophys J Int, 177: 1284-1304

Shi X, Burov E, Leroy S, Qiu X, Xia B. 2005. Intrusion and its implication for subsidence: A case from the Baiyun Sag, on the northern margin of the South China Sea. Tectonophysics, 407: 117134

Tang Q, Zheng C. 2013. Crust and upper mantle structure and its tectonic implications in the South China Sea and adjacent regions. J Asian Earth Sci, 62: 510-525

Wheeler P, White N. 2000. Quest for dynamic topography: Observations from Southeast Asia. Geology, 28: 963-966

Wheeler P, White N. 2002. Measuring dynamic topography: An analysis of Southeast Asia. Tectonics, 21: 4-1-4-26

Wang P, Li S, Suo Y, Guo L, Wang G, Hui G, Santosh M, Somerville I D, Cao X, Li Y. 2020. Plate tectonic control on the formation and tectonic migration of Cenozoic basins in northern margin of the South China Sea. GeoSci Front, 11: 1231-1251

Wang T K, Chen M K, Lee C S, Xia K Y. 2006. Seismic imaging of the transitional crust across the northeastern margin of the South China 
Sea. Tectonophysics, 412: 237-254

Wang J, Pang X, Tang D, Liu B, Xu D. 2013. Transtensional tectonism and its effects on the distribution of sandbodies in the Paleogene Baiyun Sag, Pearl River Mouth Basin, China. Mar Geophys Res, 34: 195-207

Wu S, Qiu X, Zhou D, Zeng G, Xia K, Ye S. 2009. Crustal structure beneath Yinggehai basin and adjacent Hainan Island, and its tectonic implications. J Earth Sci, 20: 13-26

Xie X, Müller R D, Li S, Gong Z, Steinberger B. 2006. Origin of anomalous subsidence along the Northern South China Sea margin and its relationship to dynamic topography. Mar Pet Geol, 23: 745765

Xia K Y, Zhou D, Su D Q, Flueh E, Ye S Y, He H Y, Chen W D, Xie Y H, Wang G X, LIU S J, Fu G, Wang J X, Chen J H. 1998. The velocity structure of the Yinggehai Basin and its hydrocarbon implication. Chin Sci Bull, 43: 2047-2054

Yang T, Gurnis M. 2016. Dynamic topography, gravity and the role of lateral viscosity variations from inversion of global mantle flow. Geophys J Int, 207: 1186-1202

Yan P, Zhou D, Liu Z A. 2001. A crustal structure profile across the northern continental margin of the South China Sea. Tectonophysics, 338: 1-21

Yan P, Liu H. 2004. Tectonic-stratigraphic division and blind fold structures in Nansha Waters, South China Sea. J Asian Earth Sci, 24: 337-348

Yu C, Shi X, Yang X, Zhao J, Chen M, Tang Q. 2017. Deep thermal structure of Southeast Asia constrained by S-velocity data. Mar
Geophys Res, 38: 341-355

Ye Q, Mei L, Shi H, Du J, Deng P, Shu Y, Camanni G. 2020. The Influence of Pre-existing Basement Faults on the Cenozoic Structure and Evolution of the Proximal Domain, Northern South China Sea Rifted Margin. Tectonics, 39: e05845

Zhao M, He E, Sibuet J C, Sun L, Qiu X, Tan P, Wang J. 2018. Postseafloor spreading volcanism in the central east South China Sea and its formation through an extremely thin oceanic crust. Geochem Geophys Geosyst, 19: 621-641

Zhao M, Qiu X, Xia S, Xu H, Wang P, Wang T K, Lee C S, Xia K. 2010. Seismic structure in the northeastern South China Sea: Swave velocity and $\mathrm{Vp} / \mathrm{Vs}$ ratios derived from three-component $\mathrm{OBS}$ data. Tectonophysics, 480: 183-197

Zhao F, Alves T M, Wu S, Li W, Huuse M, Mi L, Sun Q, Ma B. 2016. Prolonged post-rift magmatism on highly extended crust of divergent continental margins (Baiyun Sag, South China Sea). Earth Planet Sci Lett, 445: 79-91

Zhao F, Alves T M, Xia S, Li W, Wang L, Mi L, Wu S, Cao J, Fan C. 2020. Along-strike segmentation of the South China Sea margin imposed by inherited pre-rift basement structures. Earth Planet Sci Lett, 530: 115862

Zhao Z, Sun Z, Liu J, Pérez-Gussinyé M, Zhuo H. 2018. The continental extension discrepancy and anomalous subsidence pattern in the western Qiongdongnan Basin, South China Sea. Earth Planet Sci Lett, 501: 180-191

Zhou Q, Liu L. 2019. Topographic evolution of the western United States since the early Miocene. Earth Planet Sci Lett, 514: 1-12

(责任编委: 刘丽军) 